\title{
Osteoporosis Therapy: Bone Modeling during Growth and Aging
}

\author{
Toshihiro Sugiyama* and Hiromi Oda \\ Department of Orthopaedic Surgery, Saitama Medical University, Saitama, Japan
}

Keywords: mechanical strain, bone modeling, osteoporosis, romosozumab, abaloparatide

\section{MECHANICAL STRAIN: THE PRIMARY DETERMINANT OF BONE MODELING}

Remodeling-based bone resorption and formation are coupled on the same surface and contribute to calcium homeostasis, while modeling-based bone formation and resorption occur on different surfaces, such as during growth, to change skeletal shape; of importance, the aging skeleton can also include bone modeling $(1,2)$. The primary determinant of bone modeling is elastic deformation (strain) of the skeleton engendered by habitual physical activity, and accumulating evidence suggests that bones respond to mechanical loading to maintain their resultant strain (3-5). Not only osteocytes inside bone tissue but also bone-forming osteoblasts and bone-resorpting osteoclasts on the surface are responsive to mechanical signals $(6,7)$, and the modeling-based actions of osteoblasts and osteoclasts are not coupled.

Skeletal fragility depends on bone quality and quantity (8). The latter would be normally under the mechanical strain-related feedback control (3-5); Wolff's law, established more than a century ago, confirms that mechanical environment plays a key role in controlling skeletal architecture (9), and the pattern of trabecular bone in the hip (Singh index) can be used for the evaluation of osteoporosis (10). In addition, this natural homeostatic system could work against mineral-related, but not collagen-related, impairment of bone material quality $(11,12)$.

Fragility fracture associated with osteoporosis is a common health problem during growth (13, $14)$ and aging $(15,16)$. Here, we provide a novel evidence-based insight into osteoporosis therapy from the viewpoint of bone modeling/remodeling, apart from approaches targeting bone formation/ resorption and quality/quantity.

\section{IMPROVING SKELETAL FRAGILITY BY BONE MODELING}

Normal bone growth is important not only for children but also for adults to prevent age-related fragility fracture $(17,18)$. Appropriate weight-bearing physical activities and calcium/vitamin D intakes support good bone acquisition during growth, but the treatment of severe pediatric osteoporosis has been highly limited. For instance, spontaneous fracture in children with physical disability, such as cerebral palsy, is a long-standing problem that affects their quality of life (19); the latest clinical practice guideline does not recommend regular use of bisphosphonates because their long-term effects on the growing skeleton are unclear (20). Although reduced mechanical loading is the major cause of skeletal fragility in individuals with physical disability, static weight-bearing physical activities as well as calcium/vitamin D supplementation are unlikely to prevent their fragility fractures (20). Fundamental rules of mechanical strain-related stimulus include strain rate as a key determinant of the stimulus and bones respond to dynamic, but not static, mechanical loading (21).

In the management of osteoporosis in children, it is important to note that their skeleton is different from the adult skeleton. Bone growth requires bone modeling that is predominantly influenced by mechanical environment and, therefore, cortical bone in lower limbs is very thin in children 
who cannot stand and walk. Consequently, an ideal method toward a cure for skeletal fragility during growth is pharmacologically stimulating mechanical strain-related bone modeling. Furthermore, bone modeling would also be useful for adults. One unmet need in elderly patients at high risk for fracture is to improve their skeletal fragility more rapidly; in this regard, bone modeling is superior to bone remodeling as with building reinforcement rather than rebuilding generally performed against earthquakes in Japan.

\section{OSTEOPOROSIS AGENTS AND BONE MODELING}

Most osteoporosis drugs are generally linked to bone remodeling rather than bone modeling, but it appears that some of them could be associated with bone modeling directly or indirectly (22). As discussed recently, daily or weekly treatment with teriparatide would stimulate modeling-based bone formation $(11,23)$. Bone modeling also seems to be stimulated by daily treatment with abaloparatide, an investigational agent (Table 1). Interestingly, daily subcutaneous injections of teriparatide $(20 \mu \mathrm{g} /$ day $)$ and abaloparatide $(80 \mu \mathrm{g} /$ day $)$ resulted in different effects on circulating markers of bone formation and resorption; teriparatide caused a rapid and sustained increase in bone formation followed by a delayed increase in bone resorption, while abaloparatide induced a relatively transient increase in bone formation with a less prominent increase in bone resorption (24). Of note, the effects of abaloparatide are partially similar to those of weekly subcutaneous injection of teriparatide $(56.5 \mu \mathrm{g} /$ week $)$ used in Japan (11); the rapid but relatively transient increase in bone formation without the similar increase in bone resorption implies that daily treatment with abaloparatide stimulates more modeling-based bone formation compared to daily treatment with teriparatide. This is compatible with binding of abaloparatide to a $G$ proteindependent conformation of parathyroid hormone type 1 receptor with higher affinity but more transiently than teriparatide (25) and abaloparatide-induced increases in trabecular thickness and total area of cortical bone (26) and can reasonably explain greater increases in areal bone mineral density (BMD) at the femoral neck and total hip after daily treatment with abaloparatide versus

TABLE 1 | Expected effects of anabolic osteoporosis agents on bone modeling.

\begin{tabular}{|c|c|c|}
\hline Anabolic osteoporosis agents & Bone modeling & Clinical status \\
\hline \multicolumn{3}{|l|}{ Parathyroid hormone } \\
\hline \multicolumn{3}{|l|}{ Teriparatide } \\
\hline Daily $(20 \mu \mathrm{g} / \text { day })^{\mathrm{a}}$ & + & Approval \\
\hline Weekly $\left(56.5 \mu \mathrm{g} /\right.$ week $^{\mathrm{a}}$ & + & Approval $^{\mathrm{b}}$ \\
\hline \multicolumn{3}{|l|}{ Parathyroid hormone-related protein } \\
\hline Abaloparatide (daily, $80 \mu \mathrm{g} /$ day) ${ }^{\mathrm{a}}$ & ++ & Phase 3 \\
\hline \multicolumn{3}{|l|}{ Anti-sclerostin antibody } \\
\hline Romosozumab (monthly, 210 mg/month) ${ }^{a}$ & +++ & Phase 3 \\
\hline
\end{tabular}

teriparatide for 6 months (24). Accordingly, it is possible to speculate that, when teriparatide $(20 \mu \mathrm{g} /$ day $)$ and abaloparatide $(80 \mu \mathrm{g} /$ day $)$ are injected daily, the improvement of bone fragility could be faster by abaloparatide but better for longer duration by teriparatide (23), and abaloparatide rather than teriparatide might be more suitable for use in combination with denosumab (27). Nevertheless, both agents would not be used for children due to carcinogenicity in animals, though clinical experience with teriparatide has not presented such possibility in adults (28); to our knowledge, the use of teriparatide has been reported in a limited number of children with hypoparathyroidism (29), but not with osteoporosis.

In addition to teriparatide and abaloparatide, an increase in areal BMD over a prolonged period of time by treatment with osteoporosis drugs might partly result from bone modeling; examples could include denosumab $(30,31)$, strontium ranelate $(32,33)$, and investigational odanacatib (34-36). Although histomorphometric analysis of transiliac bone biopsies has not shown anabolic action of these agents, iliac bone is not a weight-bearing region as pointed out previously (33); their skeletal effects are site-specific and, therefore, iliac bone is unlikely to fully reflect each skeletal site (37).

\section{STIMULATING MECHANICAL STRAIN- RELATED BONE MODELING}

One promising therapeutic target for pharmacologically stimulating mechanical strain-related bone modeling is sclerostin (38-40), which is primarily secreted by osteocytes in the skeleton and inhibits the Wnt signaling pathway. On the basis of several lines of evidence, we have suggested that investigational anti-sclerostin antibodies, such as romosozumab $(41,42)$, possess the effect of mechanical strain-related stimulus that results in bone modeling $(34,43)$ (Table 1). This theory is supported by experimental findings that osteocyte sclerostin production is increased by skeletal disuse and decreased by skeletal loading $(44,45)$ and clinical data that circulating levels of sclerostin are higher after decreased physical activity $(46,47)$ and lower after increased physical activity $(48,49)$. High bone mass in patients with sclerostin deficiency is present throughout the skeleton, including nonweight-bearing regions, such as the face and skull (40), indicating that anti-sclerostin antibodies are not agents that decrease the mechanical strain threshold for bone modeling; treatment with an anti-sclerostin antibody is highly efficacious even under conditions with impaired physical activity (50-54), whereas enhancing skeletal response to physical activity cannot effectively improve bone fragility caused by reduced skeletal loading. Accordingly, treatment with an anti-sclerostin antibody is likely to strengthen the skeleton, without any specific direction in contrast to exercise, to prevent fall-related fractures such as in the hip (55).

Consequently, although most physically disabled individuals or elderly persons with severe osteoporosis would not perform dynamic exercise that results in bone modeling, anti-sclerostin antibodies are theoretically expected to contribute to a rapid improvement of their skeletal fragility by stimulating bone modeling. Sclerostin deficiency in humans leads to bone overgrowth 
progressively (40), and pharmacologic inhibition of sclerostin results in dose-related increases in areal $\operatorname{BMD}(41,56)$ while monthly subcutaneous injection of romosozumab at a dose of $210 \mathrm{mg}$ increased areal BMD at the lumbar spine and hip but not the radius in postmenopausal women (41), suggesting that the selected dose and interval are not enough for non-weight-bearing regions with higher levels of sclerostin expression and thus do not cause undesired bone overgrowth at the face or skull in adults. If the same treatment regimen is applied to different geographic regions, however, careful clinical practice might be needed in patients with very low body weight, such as in Asia. A higher dose and/or a shorter interval would be necessary for improving skeletal fragility in patients with physical disability, and clinical trials especially in children require careful investigation on their optimal doses and intervals; recent assessment did not find carcinogenicity risk of romosozumab (57).

\section{REFERENCES}

1. Hattner R, Epker BN, Frost HM. Suggested sequential mode of control of changes in cell behaviour in adult bone remodelling. Nature (1965) 206:489-90. doi:10.1038/206489a0

2. Baron R, Kneissel M. WNT signaling in bone homeostasis and disease: from human mutations to treatments. Nat Med (2013) 19:179-92. doi:10.1038/ nm.3074

3. Frost HM. Bone's mechanostat: a 2003 update. Anat Rec A Discov Mol Cell Evol Biol (2003) 275:1081-101. doi:10.1002/ar.a.10119

4. Meakin LB, Price JS, Lanyon LE. The contribution of experimental in vivo models to understanding the mechanisms of adaptation to mechanical loading in bone. Front Endocrinol (2014) 5:154. doi:10.3389/ fendo.2014.00154

5. Sugiyama T, Kim YT, Oda H. Skeletal adaptation to mechanical strain: a key role in osteoporosis. In: Shimada Y, Miyakoshi N, editors. Osteoporosis in Orthopedics: Assessment and Therapeutic Options. Tokyo: Springer (2016). p. 3-22.

6. Thompson WR, Rubin CT, Rubin J. Mechanical regulation of signaling pathways in bone. Gene (2012) 503:179-93. doi:10.1016/j.gene.2012.04.076

7. Klein-Nulend J, Bacabac RG, Bakker AD. Mechanical loading and how it affects bone cells: the role of the osteocyte cytoskeleton in maintaining our skeleton. Eur Cell Mater (2012) 24:278-91. doi:10.22203/eCM.v024a20

8. Seeman E, Delmas PD. Bone quality - the material and structural basis of bone strength and fragility. N Engl J Med (2006) 354:2250-61. doi:10.1056/ NEJMra053077

9. Wolff J. The Law of Bone Remodelling. Berlin: Springer-Verlag (1986). $126 \mathrm{p}$.

10. Singh M, Riggs BL, Beabout JW, Jowsey J. Femoral trabecular-pattern index for evaluation of spinal osteoporosis. Ann Intern Med (1972) 77:63-7. doi:10.7326/0003-4819-77-1-63

11. Sugiyama T, Torio T, Sato T, Matsumoto M, Kim YT, Oda H. Improvement of skeletal fragility by teriparatide in adult osteoporosis patients: a novel mechanostat-based hypothesis for bone quality. Front Endocrinol (2015) 6:6. doi:10.3389/fendo.2015.00006

12. Sugiyama T, Kono Y, Sekiguchi K, Kim YT, Oda H. Age-related fragility fracture: insights from the natural homeostatic system in the skeleton. Arch Osteoporos (2015) 10:45. doi:10.1007/s11657-015-0251-2

13. Bachrach LK, Gordon CM. Section on Endocrinology. Bone densitometry in children and adolescents. Pediatrics (2016) 138:e20162398. doi:10.1542/ peds.2016-2398

14. Ward LM, Konji VN, Ma J. The management of osteoporosis in children. Osteoporos Int (2016) 27:2147-79. doi:10.1007/s00198-016-3515-9

15. Eastell R, O'Neill TW, Hofbauer LC, Langdahl B, Reid IR, Gold DT, et al. Postmenopausal osteoporosis. Nat Rev Dis Primers (2016) 2:16069. doi:10.1038/nrdp.2016.69

16. Black DM, Rosen CJ. Clinical practice. Postmenopausal osteoporosis. N Engl J Med (2016) 374:254-62. doi:10.1056/NEJMcp1513724

\section{CONCLUSION}

The therapeutic target of osteoporosis during childhood should be bone modeling, rather than bone remodeling, that is essential for skeletal growth. Bone modeling can also contribute to rapidly improving skeletal fragility in older adults toward goal-directed treatment for osteoporosis (58), though bone modeling in younger adults might have concerns from bone remodeling point of view. Anti-sclerostin antibodies, such as romosozumab, are promising drug candidates for stimulating mechanical strain-related bone modeling during growth and aging.

\section{AUTHOR CONTRIBUTIONS}

All authors listed have made substantial, direct, and intellectual contribution to the work and approved it for publication.

17. Sugiyama T, Taguchi T. Cortical stability of the femoral neck and hip fracture risk. Lancet (2005) 366:1525-6. doi:10.1016/S0140-6736(05)67621-0

18. Weaver CM, Gordon CM, Janz KF, Kalkwarf HJ, Lappe JM, Lewis R, et al. The National Osteoporosis Foundation's position statement on peak bone mass development and lifestyle factors: a systematic review and implementation recommendations. Osteoporos Int (2016) 27:1281-386. doi:10.1007/ s00198-016-3551-5

19. Sugiyama T, Taguchi T, Kawai S. Spontaneous fractures and quality of life in cerebral palsy. Lancet (2004) 364:28. doi:10.1016/ S0140-6736(04)16585-9

20. Ozel S, Switzer L, Macintosh A, Fehlings D. Informing evidence-based clinical practice guidelines for children with cerebral palsy at risk of osteoporosis: an update. Dev Med Child Neurol (2016) 58:918-23. doi:10.1111/ dmcn.13196

21. Sugiyama T, Watarai K, Oda T, Kim YT, Oda H. Exercise for the skeleton in postmenopausal women: fundamental rules of mechanical strain-related stimulus. Osteoporos Int (2016) 27:1927-8. doi:10.1007/s00198-015-3407-4

22. Langdahl B, Ferrari S, Dempster DW. Bone modeling and remodeling: potential as therapeutic targets for the treatment of osteoporosis. Ther Adv Musculoskelet Dis (2016) 8:225-35. doi:10.1177/1759720X16670154

23. Sugiyama T, Kono Y, Sekiguchi K, Kim YT, Oda H. Full 24-month treatment course with daily teriparatide: a mechanistic insight. Osteoporos Int (2016) 27:2635-6. doi:10.1007/s00198-016-3630-7

24. Miller PD, Hattersley G, Riis BJ, Williams GC, Lau E, Russo LA, et al. Effect of abaloparatide vs placebo on new vertebral fractures in postmenopausal women with osteoporosis: a randomized clinical trial. JAMA (2016) 316:722-33. doi:10.1001/jama.2016.11136

25. Hattersley G, Dean T, Corbin BA, Bahar H, Gardella TJ. Binding selectively of abaloparatide for PTH-type-1-receptor conformations and effects on downstream signaling. Endocrinology (2016) 157:141-9. doi:10.1210/en.2015-1726

26. Bahar H, Gallacher K, Downall J, Nelson CA, Shomali M, Hattersley G. Six weeks of daily abaloparatide treatment increased vertebral and femoral bone mineral density, microarchitecture and strength in ovariectomized osteopenic rats. Calcif Tissue Int (2016) 99:489-99. doi:10.1007/s00223-016-0171-1

27. Sugiyama T, Oda H. Combination treatment with teriparatide and denosumab in osteoporosis. JClin Endocrinol Metab (2016) 101:L80-1. doi:10.1210/ jc.2016-2343

28. Elraiyah T, Gionfriddo MR, Montori VM, Murad MH. Content, consistency, and quality of black box warnings: time for a change. Ann Intern Med (2015) 163:875-6. doi:10.7326/M15-1097

29. Matarazzo P, Tuli G, Fiore L, Mussa A, Feyles F, Peiretti V, et al. Teriparatide (rhPTH) treatment in children with syndromic hypoparathyroidism. J Pediatr Endocrinol Metab (2014) 27:53-9. doi:10.1515/jpem-2013-0159

30. Papapoulos S, Lippuner K, Roux C, Lin CJ, Kendler DL, Lewiecki EM, et al. The effect of 8 or 5 years of denosumab treatment in postmenopausal women with osteoporosis: results from the FREEDOM Extension study. Osteoporos Int (2015) 26:2773-83. doi:10.1007/s00198-015-3234-7 
31. Sugiyama T, Kim YT, Oda H. A possible mechanism of denosumab treatment for fracture prevention. JClin Endocrinol Metab (2016) 101:L15-6. doi:10.1210/jc.2015-4072

32. Reginster JY, Kaufman JM, Goemaere S, Devogelaer JP, Benhamou CL, Felsenberg D, et al. Maintenance of antifracture efficacy over 10 years with strontium ranelate in postmenopausal osteoporosis. Osteoporos Int (2012) 23:1115-22. doi:10.1007/s00198-011-1847-z

33. Sugiyama T, Kim YT, Oda H. Strontium ranelate in the treatment of osteoporosis: a possible mechanism. J Clin Endocrinol Metab (2016) 101:L64-5. doi:10.1210/jc.2016-1479

34. Sugiyama T, Kim YT, Oda H. Osteoporosis therapy: a novel insight from natural homeostatic system in the skeleton. Osteoporos Int (2015) 26:443-7. doi:10.1007/s00198-014-2923-y

35. Duong le T, Leung AT, Langdahl B. Cathepsin K inhibition: a new mechanism for the treatment of osteoporosis. Calcif Tissue Int (2016) 98:381-97. doi:10.1007/s00223-015-0051-0

36. Rizzoli R, Benhamou CL, Halse J, Miller PD, Reid IR, Rodriguez Portales JA, et al. Continuous treatment with odanacatib for up to 8 years in postmenopausal women with low bone mineral density: a phase 2 study. Osteoporos Int (2016) 27:2099-107. doi:10.1007/s00198-016-3503-0

37. Chavassieux P, Portero-Muzy N, Roux JP, Garnero P, Chapurlat R. Are biochemical markers of bone turnover representative of bone histomorphometry in 370 postmenopausal women? J Clin Endocrinol Metab (2015) 100:4662-8. doi:10.1210/jc.2015-2957

38. Ke HZ, Richards WG, Li X, Ominsky MS. Sclerostin and dickkopf-1 as therapeutic targets in bone diseases. Endocr Rev (2012) 33:747-83. doi:10.1210/ er.2011-1060

39. Lerner UH, Ohlsson C. The WNT system: background and its role in bone. J Intern Med (2015) 277:630-49. doi:10.1111/joim.12368

40. Appelman-Dijkstra NM, Papapoulos SE. From disease to treatment: from rare skeletal disorders to treatments for osteoporosis. Endocrine (2016) 52:414-26. doi:10.1007/s12020-016-0888-7

41. McClung MR, Grauer A, Boonen S, Bolognese MA, Brown JP, Diez-Perez A, et al. Romosozumab in postmenopausal women with low bone mineral density. N Engl J Med (2014) 370:412-20. doi:10.1056/NEJMoa1305224

42. Cosman F, Crittenden DB, Adachi JD, Binkley N, Czerwinski E, Ferrari S, et al. Romosozumab treatment in postmenopausal women with osteoporosis. N Engl J Med (2016) 375:1532-43. doi:10.1056/NEJMoa1607948

43. Sugiyama T, Torio T, Miyajima T, Kim YT, Oda H. Romosozumab and blosozumab: alternative drugs of mechanical strain-related stimulus toward a cure for osteoporosis. Front Endocrinol (2015) 6:54. doi:10.3389/fendo.2015.00054

44. Robling AG, Turner CH. Mechanical signaling for bone modeling and remodeling. Crit Rev Eukaryot Gene Expr (2009) 19:319-38. doi:10.1615/ CritRevEukarGeneExpr.v19.i4.50

45. Moustafa A, Sugiyama T, Prasad J, Zaman G, Gross TS, Lanyon LE, et al. Mechanical loading-related changes in osteocyte sclerostin expression in mice are more closely associated with the subsequent osteogenic response than the peak strains engendered. Osteoporos Int (2012) 23:1225-34. doi:10.1007/ s00198-011-1656-4

46. Gaudio A, Pennisi P, Bratengeier C, Torrisi V, Linder B, Mangiafico RA, et al. Increased sclerostin serum levels associated with bone formation and resorption markers in patients with immobilization-induced bone loss. J Clin Endocrinol Metab (2010) 95:2248-53. doi:10.1210/ jc. 2010-0067
47. Spatz JM, Fields EE, Yu EW, Divieti Pajevic P, Bouxsein ML, Sibonga JD, et al. Serum sclerostin increases in healthy adult men during bed rest. J Clin Endocrinol Metab (2012) 97:E1736-40. doi:10.1210/jc.2012-1579

48. Amrein K, Amrein S, Drexler C, Dimai HP, Dobnig H, Pfeifer K, et al. Sclerostin and its association with physical activity, age, gender, body composition, and bone mineral content in healthy adults. J Clin Endocrinol Metab (2012) 97:148-54. doi:10.1210/jc.2011-2152

49. Ardawi MS, Rouzi AA, Qari MH. Physical activity in relation to serum sclerostin, insulin-like growth factor-1, and bone turnover markers in healthy premenopausal women: a cross-sectional and a longitudinal study. J Clin Endocrinol Metab (2012) 97:3691-9. doi:10.1210/jc.2011-3361

50. Tian XY, Jee WS, Li X, Paszty C, Ke HZ. Sclerostin antibody increases bone mass by stimulating bone formation and inhibiting bone resorption in a hindlimb-immobilization rat model. Bone (2011) 48:197-201. doi:10.1016/j. bone.2010.09.009

51. Shahnazari M, Wronski T, Chu V, Williams A, Leeper A, Stolina M, et al. Early response of bone marrow osteoprogenitors to skeletal unloading and sclerostin antibody. Calcif Tissue Int (2012) 91:50-8. doi:10.1007/s00223-012-9610-9

52. Spatz JM, Ellman R, Cloutier AM, Louis L, van Vliet M, Suva LJ, et al. Sclerostin antibody inhibits skeletal deterioration due to reduced mechanical loading. J Bone Miner Res (2013) 28:865-74. doi:10.1002/jbmr.1807

53. Beggs LA, Ye F, Ghosh P, Beck DT, Conover CF, Balaez A, et al. Sclerostin inhibition prevents spinal cord injury-induced cancellous bone loss. J Bone Miner Res (2015) 30:681-9. doi:10.1002/jbmr.2396

54. Qin W, Li X, Peng Y, Harlow LM, Ren Y, Wu Y, et al. Sclerostin antibody preserves the morphology and structure of osteocytes and blocks the severe skeletal deterioration after motor-complete spinal cord injury in rats. J Bone Miner Res (2015) 30:1994-2004. doi:10.1002/jbmr.2549

55. Sugiyama T, Watarai K, Oda T, Kim YT, Oda H. Possible different roles of exercise in preventing vertebral and hip fractures. Osteoporos Int (2016) 27:3135-6. doi:10.1007/s00198-016-3628-1

56. Recker RR, Benson CT, Matsumoto T, Bolognese MA, Robins DA, Alam J, et al. A randomized, double-blind phase 2 clinical trial of blosozumab, a sclerostin antibody, in postmenopausal women with low bone mineral density. J Bone Miner Res (2015) 30:216-24. doi:10.1002/jbmr.2351

57. Chouinard L, Felx M, Mellal N, Varela A, Mann P, Jolette J, et al. Carcinogenicity risk assessment of romosozumab: a review of scientific weight-of-evidence and findings in a rat lifetime pharmacology study. Regul Toxicol Pharmacol (2016) 81:212-22. doi:10.1016/j.yrtph.2016.08.010

58. Cummings SR, Cosman F, Lewiecki EM, Schousboe JT, Bauer DC, Black DM, et al. Goal-directed treatment for osteoporosis: a progress report from the ASBMR-NOF working group on goal-directed treatment for osteoporosis. J Bone Miner Res (2017) 32:3-10. doi:10.1002/jbmr.3039

Conflict of Interest Statement: The authors declare that the research was conducted in the absence of any commercial or financial relationships that could be construed as a potential conflict of interest.

Copyright $(2017$ Sugiyama and Oda. This is an open-access article distributed under the terms of the Creative Commons Attribution License (CC BY). The use, distribution or reproduction in other forums is permitted, provided the original author(s) or licensor are credited and that the original publication in this journal is cited, in accordance with accepted academic practice. No use, distribution or reproduction is permitted which does not comply with these terms. 